\title{
Regulation of CD43-induced U937 homotypic aggregation
}

\author{
Jae Youl Cho, ${ }^{\mathrm{a}, 1}$ Benjamin M. Chain, ${ }^{\mathrm{a}}$ Jordi Vives, ${ }^{\mathrm{b}}$ Vaclav Horejsi, ${ }^{\mathrm{c}}$ and David R. Katz ${ }^{\mathrm{a}, *}$ \\ ${ }^{a}$ Department of Immunology of Molecular Pathology, Windeyer Institute of Medical Sciences, \\ University College London, 46 Cleveland Street, London W1T 6JF, UK \\ ${ }^{\mathrm{b}}$ Servei de Immunologia, Hospital Clinic i Provincial, Barcelona, Spain \\ ${ }^{\mathrm{c}}$ Institute of Molecular Genetics, Academy of Sciences of the Czech Republic, Prague, Czech Republic
}

Received 14 April 2003, revised version received 28 May 2003

\begin{abstract}
CD43 (leukosialin, sialophorin), a prominent component of the hemopoietic cell surface, has an enigmatic role in cell-cell interaction. The observation that CD43 ligation triggers homotypic aggregation of monoblastoid U937 cells has permitted analysis of this: CD43induced aggregation was distinguishable from CD29- (also known as $\beta 1$ integrin) or CD98- (also known as 4F2, or fusion-related protein 1 ) induced aggregation, with different energy requirements and with partial dependence on $\beta 2$ integrins. Previous studies have focused on the role of CD43 ligation in tyrosine phosphorylation. However, in the homotypic adhesion assay, although there is initial tyrosine phosphorylation, protein tyrosine kinase inhibitors did not block aggregation. Therefore, other signaling pathways were examined. CD43 ligation induced protein tyrosine dephosphorylation, and protein tyrosine phosphatase inhibitors blocked aggregation. Activation of MAP kinases was not necessary. Cytoskeletal inhibitors amplified aggregation. Protein kinase C (PKC) inhibitors amplified aggregation, implicating PKC as a negative regulator. CD43 ligation up-regulated surface adhesion molecules and enhanced CD29- and CD98-induced aggregation. Thus, CD43 participation in cell-cell adhesion is under stringent control, involving both surface events and several different intracellular signaling pathways, acting together to regulate the process. These mechanisms add a further dimension to the potential role of CD43 in tissue immune responses.
\end{abstract}

(C) 2003 Elsevier Inc. All rights reserved.

Keywords: Clustering; CD43; CD98; Signaling; Tyrosine phosphorylation; Phosphatase; Protein kinase C; Adhesion; Integrin

\section{Introduction}

Cell-cell and cell-matrix adhesive interactions play an important role in many different aspects of immunobiology. These interactions are involved in cell localization, effector recognition, and activation phenomena [1,2]. Examples of major adhesive interactions are those between $\mathrm{T}$ cells and antigen-presenting cells [3], between cytotoxic $\mathrm{T}$ cells and their targets [4], and between lymphocyte and endothelium [5]. Thus it is not surprising that recent studies have shown that cell adhesion is a strictly regulated process with multiple modes of control. These include expression of cell

\footnotetext{
* Corresponding author. Department of Immunology, Windeyer Institute of Medical Sciences, UCL, 46 Cleveland St. London W1T 4JF, UK.

E-mail address: d.katz@ucl.ac.uk (D.R. Katz).

${ }^{1}$ Present address: School of Biotechnology and Bioengineering, Kangwon National University, Kangwon-Do, 200-701, Korea.
}

adhesion receptors such as the very late antigen (VLA) $\beta 1$ (CD29) integrins and L-selectin (CD62L) [6] and of the ligands for these receptors such as intercellular adhesion molecule-1 (ICAM-1) (CD54), vascular cell adhesion molecule-1 (VCAM-1) (CD106), and E-selectin (CD62E) [7].

An important component of these interactions, less well understood, is the role of the sialomucin glycoproteins. Of these proteins, perhaps the most prominent is the CD43 molecule, also known as leukosialin, or sialophorin. The abundance on the surface of hematopoietic cells, the size of the molecule, and the glycosylation pattern all suggest a role in cell-cell contact, and one possibility is that CD43 acts as a steric barrier that inhibits such contact [8]. Abnormalities of CD43 have also been implicated in disease, in particular in Wiskott-Aldrich syndrome, where the glycosylation pattern is altered $[9,10]$.

A key question about CD43, which remains controver- 
sial, is whether CD43 has a proadhesive or an antiadhesive effect [11-13]. CD43-deficient T cells have increased adhesive properties both in vitro and in vivo [14-16], suggesting that cell surface CD43 is inhibitory, that is, is antiadhesive. CD43 mAbs have been shown to enhance homotypic aggregation previously, which could be due to masking of an antiadhesive process, but could also be due to a cross-linking proadhesive effect [17-21]. CD43 is also known to play a role in several of the basic biological properties of the cell, such as cell proliferation and apoptosis, and it has been suggested that this is mediated via activation of signaling pathways following surface ligation. Both tyrosine and serine/threonine phosphorylation have been implicated [22-24]. These activation and signaling pathways have been characterized not only in terms of the transcription factors that are implicated but also in terms of responder genes, such as IL-2. It is also known that the cytoplasmic portion of CD43 interacts with actin filaments via the ezrin/radix/moesin (ERM) family members, suggesting that CD43 could regulate cytoskeletal reorganization or, alternatively, itself be modulated during cell motility [25-27].

With respect to monocytes and macrophages, the role of CD43 has only occasionally been investigated in as much detail, although similar effects have been reported [18]. Several laboratories, however, have reported expression of the molecule on the surface of the monoblastoid cell line U937. CD43 mAbs trigger homotypic aggregation of these cells [28-30], but the signaling mechanisms involved in this aggregation, and their relationship to the other signaling and integrin pathways that have been documented with respect to CD43, have not been explored.

In this study, therefore, we have investigated these latter questions. Our findings suggest that CD43-induced homotypic aggregation is independent of conventional activation signaling pathways, such as protein tyrosine kinase (PTK), protein kinase $\mathrm{C}(\mathrm{PKC})$, and mitogen activated protein kinase (MAPK). Some of these pathways may in fact have a down-regulatory role on any proadhesive effects of the CD43 mAb. In contrast, the predominant event linked to aggregation is activation of protein tyrosine dephosphorylation. Furthermore, CD43 ligation is associated with increase in expression of several molecules that are now known to be involved in the homotypic adhesion process [31] and synergizes with them in promoting local aggregate formation.

\section{Materials and methods}

\section{Materials}

Chlorpromazine, colchicine $(\mathrm{CO})$, cycloheximide $(\mathrm{CH})$, cytochalasin B (CT), deoxyglucose (DG), ethylenediaminetetraacetic acid (EDTA), forskolin, genistein, herbimycin A, 3-(4,5-dimethylthiazol-2-yl)-2,5-diphenyltetrazolium bromide
(MTT), prostaglandin $\mathrm{E}_{2}\left(\mathrm{PGE}_{2}\right)$, and staurosporine were purchased from Sigma Chemical Co. (St. Louis, MO). Calphostin C, dephostatin, D609, H-7, H-89, KT5720, myristoylated protein kinase C inhibitor 19-27, PD98059, potassium bisperoxo-(1,10-phenanthroline)-oxovanadate [bpV(phen)], rottlerin, SB203580, and W-7 were from Calbiochem (San Diego, CA). Fetal calf serum (FCS) and RPMI 1640 were obtained from Gibco (Grand Island, NY). U937, the human promonocytic cell line, was purchased from ATCC (Rockville, MD).

\section{Antibodies}

Antibodies against cell surface molecules used in this study were prepared in the authors' laboratories, obtained from the VIIth Human Leukocyte Differentiation Antigen Workshop, or a gift of the originators as indicated. The CD43 (leukosialin, sialophorin) antibodies used were 1481B6 (ascites, IgG1); 148-1C3 (ascites, IgG2a); 148-3D4 (ascites, IgG1); 161-46 (ascites, IgG1); 84-3C1 (ascites, IgG1); MEM-59 (purified mAb, IgG1); RPD/AD9 (ascites, IgG1k); and HI161 (supernatant and ascites, IgG1). All these mAbs were defined by their ability to bind to cells transfected with human CD43; all recognize neuraminidasesensitive epitopes, and HI161 and MEM-59 are competitive for the same epitope in cross-blocking experiments [32]. Other antibodies used detected CD14 (ZCH-7-2F9, IgG1, Tang, Y); CD18 ( $\beta 2$ integrin) (CLB-LFA1, ascites, IgG1; and BU86, ascites, IgG1, gift of D. Hardie, University of Birmingham, Birmingham, UK); CD29 ( $\beta 1$ integrin) (MEM-101A, ascites, IgG1; MAR4, ascites, IgG1; and P5D5, purified antibody, $\operatorname{IgG} 1$, purified $\mathrm{mAb}$, gift of Prof. N. Hogg, ICRF, London, UK); CD44 (E1/2, purified mAb, IgG1, from Leinco Technologies [St. Louis, MO], and P2A1, purified mAb, IgG2a, from GeneTex [San Antonio, TX]; CD98 (4F2, fusion-related protein 1) (BU89, purified $\mathrm{mAb}, \mathrm{IgG1}$, gift of D. Hardie; MEM-108, ascites, IgG1; and AHN-18, purified mAb, IgG1 gift of Prof. K. Skubitz, University of Minnesota, Minnesota, MN); CD147 (MEM$\mathrm{M} 6 / 1$, ascites, IgG1; and H84HF, ascites, IgG2b, gift of Prof. K. Sagawa, Kurume University, Fukuoka, Japan). For signaling studies, anti-PKC $\zeta$ was purchased from Santa Cruz Biotechnology (Santa Cruz, CA). ERK-1/2, rabbit polyclonal IgG, and anti-phosphotyrosine, mouse monoclonal IgG2b, were from Upstate Biotechnology (Lake Placid, NY). Phospho-ERK-1/2 (rabbit anti-active MAPK (pTEpY) was from Promega (Madison, WI). Anti-PKC ( $\alpha, \beta$, and $\delta$, all mouse $\mathrm{IgG} 2 \mathrm{~b}$ ) antibodies were from Transduction Laboratories (Lexington, KY). Secondary antibodies (peroxidase-conjugated and fluorescein isothiocyanate [FITC]-conjugated rabbit anti-mouse immunoglobulin or swine antirabbit immunoglobulin) were from DAKO (Dakopatts, High Wycombe, UK). FITC-conjugated CD18 and antiHLA-DR and TRITC-conjugated CD29 were obtained from Immunotech (Marseille, France) and Coulter Electronics (Bedfordshire, UK), respectively. FITC-mouse anti-human 
CD45 and anti-human CD147 were obtained from Serotec (Oxford, UK) and Ancell Corporation (Bayport, MN). Biotin-labeled CD98-ANH-18 was prepared following a standard protocol [31].

\section{Cell culture}

U937 cells were maintained in RPMI 1640 supplemented with $10 \%$ FCS. Cells were grown at $37^{\circ} \mathrm{C}$ in $5 \% \mathrm{CO}_{2}$ and humidified air, and passaged three times a week.

\section{Quantitative homotypic cell aggregation assay}

The quantitative homotypic aggregation assay was performed as outlined previously [31]. Briefly, $20 \mu \mathrm{l}$ of cells (RPMI 1640 supplemented with $10 \%$ FCS, $10^{6}$ cells $/ \mathrm{ml}$ ) was placed in round-bottom wells of a 96-microwell plate. An equal volume of medium, with or without appropriate antibody (i.e., including test antibodies and isotype controls), was added, and the cells were incubated at $37^{\circ} \mathrm{C}$ for 1-7 h. The cells were resuspended gently, so as not to break up the clusters, and the numbers of unaggregated and total cells were counted in a hemocytometer. The percentage of cells in aggregates was determined using the equation: $\%$ of cells in aggregates $=$ [total cells - free cells/total cells $] \times$ 100. All values are expressed as means \pm SEM and were obtained from three to six replicate cultures. The Student's $t$ test for unpaired observation between control and experimental samples was carried out for statistical evaluation of a difference. Each individual experiment was repeated a minimum of three times.

\section{Cytofluorometric analysis}

Expression of CD43 on the surface of U937 cells was determined by indirect immunofluorescence and flow cytometry. Cells $\left(10^{6}\right)$ were washed with phosphate-buffered saline (PBS) staining buffer (containing 2\% FCS and $0.1 \%$ sodium azide) and incubated in $50 \mu \mathrm{l}$ of staining buffer $/ 10 \%$ rabbit serum for $10 \mathrm{~min}$ on ice. The primary antibody was added for an additional $45 \mathrm{~min}$. After being washed three times with staining buffer, cells were incubated with $1 / 20$ dilution of FITC-conjugated rabbit anti-mouse $\operatorname{IgG}$ for 45 min on ice. The cells were washed again three times with staining buffer and analyzed on a FACScan (Becton Dickinson, San Jose, CA). To examine expression of CD29, CD18, CD98, CD147, CD45, and HLA-DR, cells were also washed in staining buffer, incubated in $10 \%$ rabbit serum, and then in directly labeled FITC antibodies, before flow cytometry as above.

\section{Cell viability}

Cell viability was measured using a standard MTT assay. Ten microliters of MTT solution $(10 \mathrm{mg} / \mathrm{ml}$ in PBS) was added to each well of U937 cultures for $3 \mathrm{~h}$ before the end of the culture period. The cells were lysed by the addition of $15 \%$ sodium dodecyl sulfate (SDS) for solubilization of formazan and the optical density at $570 \mathrm{~nm}\left(\mathrm{OD}_{570-630}\right)$ was measured using a Spectramax 250 microplate reader (Molecular Devices, Sunnyvale, CA).

\section{Western blotting}

Cells $\left(5 \times 10^{6}\right.$ cells $\left./ \mathrm{ml}\right)$ were washed three times in cold PBS containing $1 \mathrm{mM}$ sodium orthovanadate and $1 \mathrm{mM}$ $\mathrm{NaF}$ and lysed in lysis buffer $(20 \mathrm{mM}$ Tris- $\mathrm{HCl}, \mathrm{pH} 7.4,2$ mM EDTA, 2 mM EGTA, $50 \mathrm{mM} \beta$-glycerophosphate, 1 $\mathrm{mM}$ sodium orthovanadate, $1 \mathrm{mM}$ dithiothreitol, $1 \%$ Triton $\mathrm{X}-100,10 \%$ glycerol, $10 \mu \mathrm{g} / \mathrm{ml}$ leupeptin, $10 \mu \mathrm{g} / \mathrm{ml}$ aprotinin, $10 \mu \mathrm{g} / \mathrm{ml}$ pepstatin, $1 \mathrm{mM}$ benzimide, and $2 \mathrm{mM}$ hydrogen peroxide) for $30 \mathrm{~min}$ with rotation in cold room. The lysates were clarified by centrifugation at $16,000 \mathrm{~g}$ for $10 \mathrm{~min}$ at $4^{\circ} \mathrm{C}$ and stored at $-20^{\circ} \mathrm{C}$ until needed. Cell lysates were analyzed by immunoblotting. Proteins (40 or $80 \mu \mathrm{g} / \mathrm{lane}$ ) were separated on $10 \%$ SDS-polyacrylamide gels and transferred by electroblotting to a nitrocellulose membrane. Membranes were blocked for $60 \mathrm{~min}$ in Trisbuffered saline containing 3\% BSA (for phosphotyrosine) or $5 \%$ nonfat milk proteins (for phospho-MAPKs), $20 \mathrm{mM}$ $\mathrm{NaF}, 2 \mathrm{mM}$ EDTA, $0.2 \%$ Tween 20 at room temperature. The blots were probed with antibodies that recognize active, phosphorylated ERK1 and ERK2 (1:4000); active, phosphorylated p38 (1:1000) and phosphotyrosine (1:2000). Unless otherwise indicated, blots were incubated with primary antibody for $1-2 \mathrm{~h}$, followed by appropriate secondary antibody (1:2-3000) for $1 \mathrm{~h}$. After incubations with either primary or secondary antibodies, blots were washed three times, for $15 \mathrm{~min}$ each. All proteins were visualized by chemiluminescence detection (ECL reagents, Amersham, Buckinghamshire, UK). Intensity of bands on film was quantitated using Synpotic Ltd. (Cambridge, UK) image analysis system and software.

\section{Results}

CD43 antibodies trigger U937 homotypic aggregation, but do not cause loss of cell viability

Our initial studies were based on our previous observation that CD43 did indeed induce homotypic aggregation of U937 cells [31]. In the present study a panel of eight mAbs specific for CD43 were tested for their ability to induce homotypic aggregation of U937 cells. The results are shown in Fig. 1.

In Fig. 1A four mAbs (161-46, HI161, 84-3C1, and MEM-59; panels 6-9, respectively) (all of which recognize the 110-kDa CD43 isoform) [32] were potent inducers of homotypic U937 aggregation, and four (148-1B6, 148-1C3, 148-3D4, and RPD/AD9; panels 3-5 and 10, respectively) were not. Positive controls included both CD29 and CD98, 
(A)

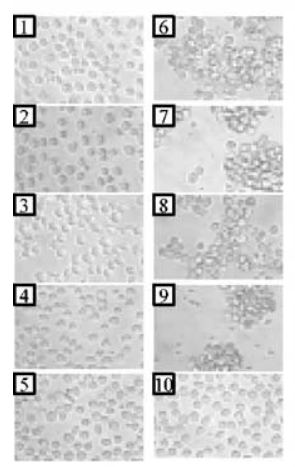

(B)

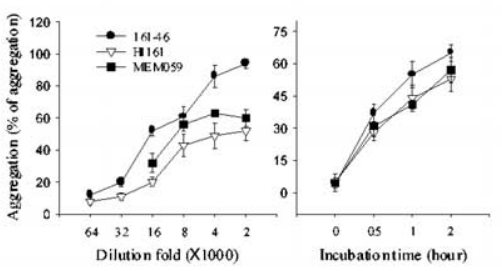

(C)

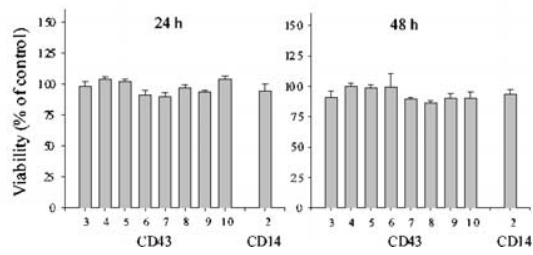

Fig. 1. CD43 ligation with antibodies induces homotypic aggregation but no change in cell viability. (A) A panel of eight CD43 mAbs were tested for their ability to induce U937 homotypic aggregation. U937 cells were incubated with mAbs (between 1.0 and $1.5 \mu \mathrm{g} / \mathrm{ml}$ in each case) for $3 \mathrm{~h}$, as described under Materials and methods. Images of cells in culture at this time point were obtained using an inverted phase contrast microscope, attached to a video camera, and captured using NIH Image software. (1) Medium alone; (2) CD14 (ZCH-7- 2F9). (3-10) CD43 mAbs: (3) 148-1B6, (4) 148-1C3, (5) 148-3D4, (6) 161-46, (7) MEM-59, (8) HI161, (9) 843C1, (10) RDP/AD9. (B) U937 cells were incubated with CD43 mAbs (161-46, HI161, and MEM-59, $0.3 \mu \mathrm{g} / \mathrm{ml}$ ) at various concentrations and for different times as indicated. Aggregation was measured as described under Materials and methods. The results show mean aggregation from triplicate cultures for representative experiments. (C) U937 cells were incubated with a panel of CD43 mAbs or an isotype control for $24 \mathrm{~h}$. Cell viability was tested by the conventional MTT assay. The results show mean \pm SD for triplicate cultures from a representative experiment. (2) CD14 (ZCH-7-2F9), (3-10) CD43 mAbs: (3) 148-1B6, (4) 148-1C3, (5) 1483D4, (6) 161-46, (7) MEM-59, (8) HI161, (9) 84-3C1, (10) RDP/AD9.

which did induce homotypic U937 aggregation [31]. Aggregation was unlikely to be due simply to the presence of an antibody against any abundant cell surface molecule found on U937 cells or to Fc receptor binding, as several antibodies to other molecules that were also abundant on the cell surface, such as CD44, did not induce aggregation. A representative example of this is shown in panel 2, where the isotype-matched control CD14 mAb does not trigger aggregation.

The features of the homotypic aggregation induced by these mAbs were examined in more detail. The results are shown in Fig. 1B. Aggregation increases in a time- and dose-dependent manner. At the highest concentration the 161-46 mAb induced aggregation of more than $80 \%$. HI161 and MEM-59, which recognize the same CD43 epitope, showed very similar aggregation-inducing effects, in terms of both dose and time course.

The effects of these mAbs were also evaluated to see whether or not CD43 ligation had induced cell death. Fig. $1 \mathrm{C}$ shows that all CD43 mAbs tested did not affect cell viability, as determined by MTT assays performed at 24 and $48 \mathrm{~h}$ after adding the mAbs to the cultures.
Homotypic aggregation does not correlate with the level of binding of CD43 mAbs to the surface of U937 cells

One possible explanation for these findings was that the mAbs showed different quantitative binding profiles on U937 cells and that there was a correlation between quantitative expression, capacity for cross-linking of cells by bivalent antibodies, and aggregation. Therefore, flow cytometry comparing the different mAbs was performed, and the results of a representative experiment are shown in Fig. 2. The mean fluorescent intensity (MFI) is very similar for all the mAbs, was similar over a range of concentrations (data not shown), and did not correlate with aggregating ability.

Another possible explanation is that CD43 can be modified in the presence of antibody. For example, shedding of CD43 has been reported following stimulation of both lymphocytes and neutrophils [33,34]. Internalization has also been reported [12]. Either of these events could diminish any antiadhesive function, via decrease in surface charge. To investigate this we examined the MFI of binding of the aggregating CD43 mAbs, where any decrease might suggest loss of CD43 from the cell surface. For these experiments, both aggregating (HI161, MEM-59, and 161-46) and "nonaggregating" (RPD/AD9) antibodies were used. Fig. 2B shows that there was indeed a decrease in MFI levels with time compared to the controls at $1 \mathrm{~h}$ for three of the four mAbs, but that this did not correlate with the aggregating properties of the mAbs. Two of the aggregating mAbs (HI161 and MEM-59) and one mAb that does not cause aggregation (RPD/AD9) showed this decrease, whereas binding of the third aggregating $\mathrm{mAb}(161-46)$ increased up to $30 \%$ in a time-dependent manner. Thus, neither proteolytic shedding alone nor internalization could account for the homotypic aggregation.

\section{CD43-induced homotypic U937 aggregation is different from CD29- and CD98-induced aggregation}

The metabolic requirements for induction of homotypic U937 aggregation by CD43 were compared with those for the homotypic aggregation induced by CD29 and CD98. Fig. 3A shows that the CD43 effect was different from the other aggregation-inducing $\mathrm{mAbs}$ in that it was insensitive to deoxyglucose, colchicine, and EDTA. Like CD29 and CD98, it was sensitive to low temperature but insensitive to cycloheximide.

With respect to cytochalasin $\mathrm{B}$, the results were also different with the CD43 mAbs. High concentrations of cytochalasin B (which cause disruption of actin filaments and inhibition of actin polymerization and which would thus also inhbit CD43 internalization after ligation) enhance aggregation, whereas CD29- and CD98-induced aggregation was sensitive even to low concentrations of cytochalasin $B$ (Figs. 3A and B). To confirm this unexpected finding further, the effects of the calmodulin inhibitors W-7 and chlor- 
(A)
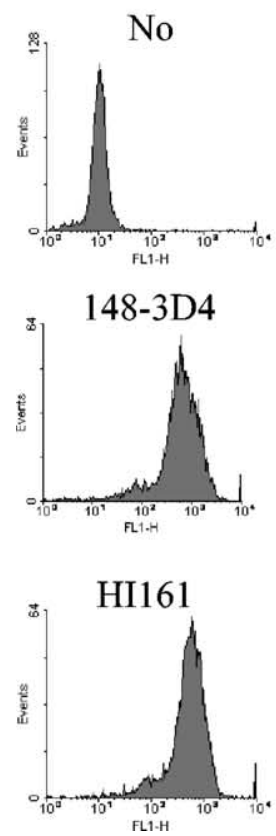

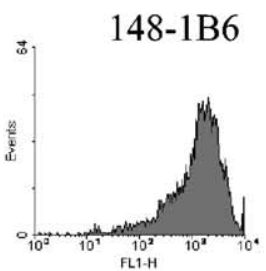

$161-46$
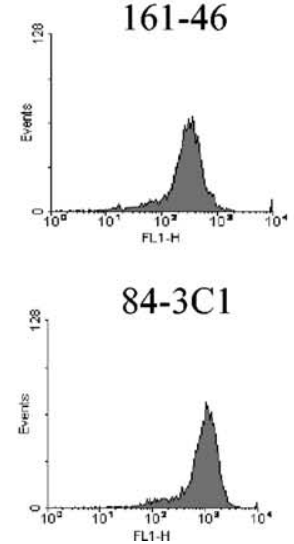

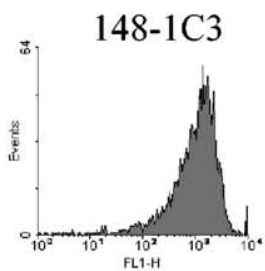

MEM-59

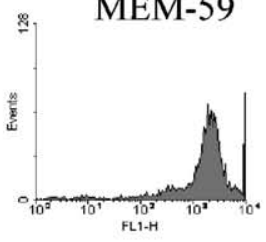

RPD/AD9

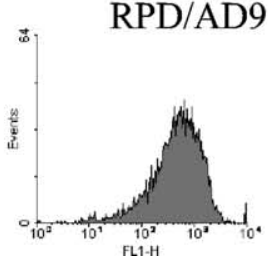

(B)

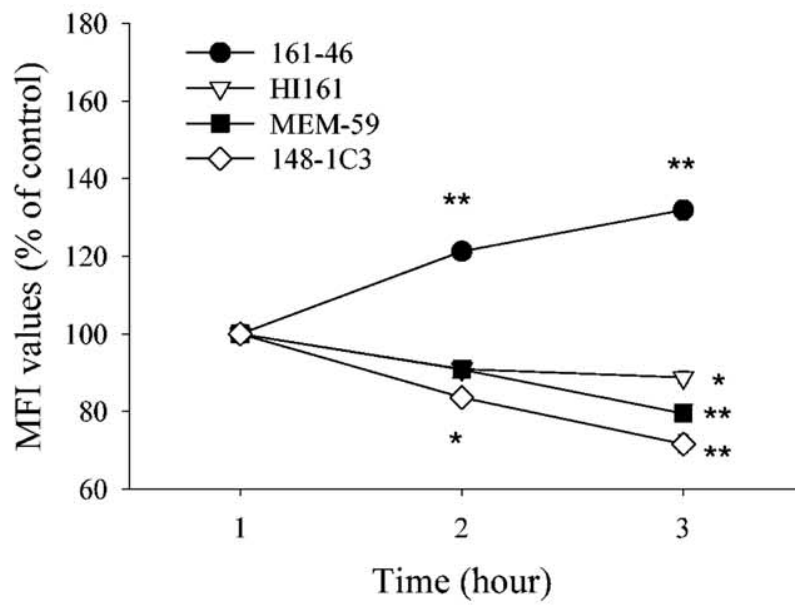

Fig. 2. Homotypic aggregation is not correlated with increased ability of mAbs to bind to the surface of U937 cells. (A) A panel of eight CD43 antibodies were tested for their ability to bind to U937 cells using flow cytometry. All antibodies were tested over a range of concentrations (1-5 $\mu \mathrm{g} / \mathrm{ml})$, and the histograms shown are of a representative experiment at the saturating dose. MFI values were calculated using WIN-MDI software on a minimum of 7500 cells. (B) To test for shedding of CD43 after ligation, three known aggregating (161-46, HI161, and MEM-59) and one nonaggregating (148-1C3) mAbs were incubated over a range of different concentrations (1-5 $\mathrm{g} / \mathrm{ml}$ ) with U937 cells for the time period indicated (up to $3 \mathrm{~h}$ ). Then CD43 expression was measured using FITC-labeled secondary antibody, followed by flow cytometry. Results of a representative experiment are expressed as percentages of control expression MFI level at Time 0 with the same mAb. MFI values were calculated using WIN-MDI software on a minimum of 7500 cells.

promazine (which inhibit myosin light chain phosphorylation and thus suppress actin polymerization) [35] were investigated. Both reagents potentiated CD43- induced homotypic aggregation (Fig. 3C). Thus, homotypic aggregation induced by CD43 appears to act via a completely different mechanism from that seen with the mAbs against the other two molecules.

\section{CD43 induces rapid tyrosine phosphorylation and} tyrosine phosphatase activity, but only tyrosine phosphatase activity is linked to induction of homotypic aggregation

Since previous studies have identified tyrosine phosphorylation as a downstream event in CD43-induced signaling $[29,30,36]$, the next experiments explored this question. The results are shown in Fig. 4A. There is both enhanced and reduced tyrosine phosphorylation of several proteins in the presence of the CD43 (161-46) $\mathrm{mAb}$, in a time-dependent fashion. Two bands (MW $\sim 49$ and $\sim 46 \mathrm{kDa}$ ) are increased over $30 \mathrm{~min}$, and two other bands (MW $\sim 60$ and $\sim 56 \mathrm{kDa}$ ) are decreased.

To document a link between the tyrosine phosphorylation that does occur, as shown, with homotypic U937 aggregation, the effect of the PTK inhibitors genistein and herbimycin A was also explored. Fig. 4B shows that these inhibitors did not suppress CD43-induced aggregation, even though they do inhibit the changes in phosphorylation seen in Fig. 4A (data not shown). This suggests that tyrosine phosphorylation per se was not necessary for CD43-induced homotypic aggregation.

However, the selective dephosphorylation of the $\sim$ p60 and $\sim$ p56 proteins shown here, and previous studies that showed that dephosphorylation at tyrosine residues can alter cell adhesion [37-39], prompted the use of inhibitors of protein tyrosine phosphatase $[40,41]$, in the aggregation assay. Both the protein tyrosine phosphatase inhibitory compounds $\mathrm{bpV}(\mathrm{phen})$ and dephostatin interrupted homotypic cell aggregation, as illustrated in Fig. 4C. This was effect was dose-dependent (Figs. 4D and E) and was also demonstrable when the cells were treated with CD43 for up to 90 min (data not shown).

\section{Inhibition of several different PKC isoforms potentiates CD43-induced aggregation}

To test other regulatory signals induced by CD43 ligation, the involvement of serine/threonine phosphorylation in homotypic U937 aggregation was examined in the presence of $\mathrm{mAb}$, with or without the H-7 and H-89 inhibitors. 
(A)

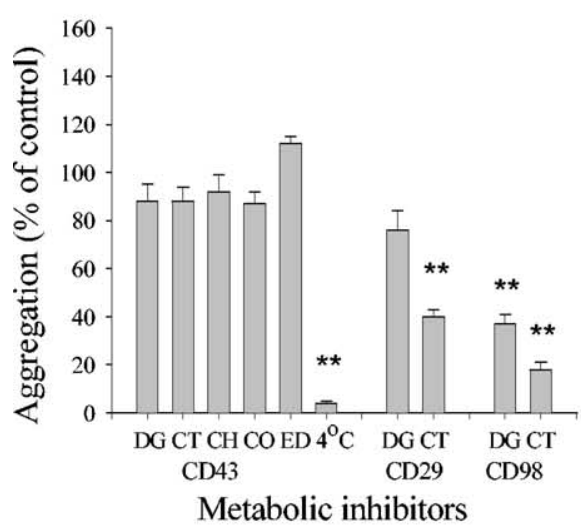

(B)

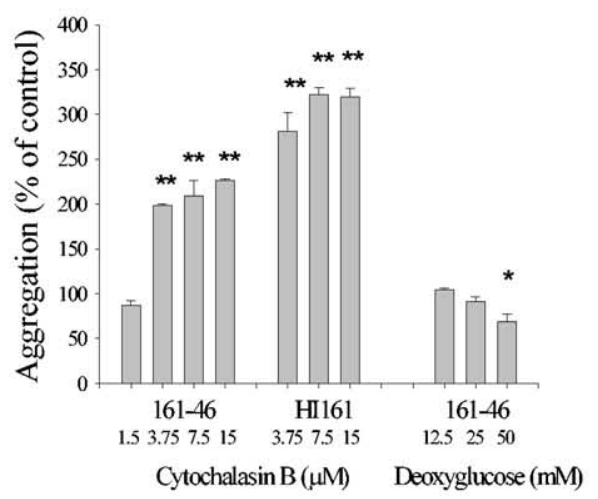

(C)

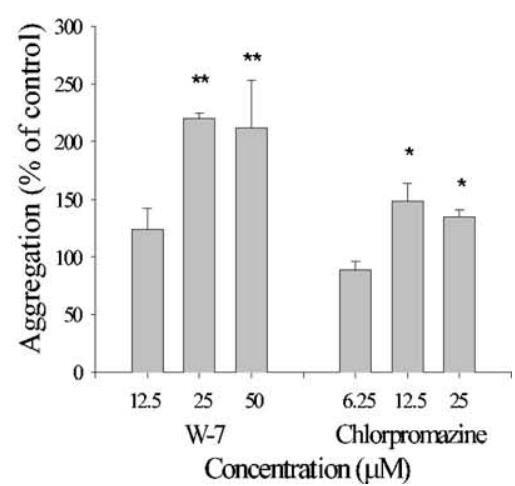

Fig. 3. CD43-induced aggregation is distinguished from CD98 and CD29 aggregation in terms of cytoskeletal involvement. (A) U937 cell homotypic aggregation was measured under standard conditions as described under Materials and methods, in the presence of CD43 (161-46, 1.0 $\mu \mathrm{g} / \mathrm{ml}), \mathrm{CD} 98-\mathrm{AHN}-18$ $(1.5 \mu \mathrm{g} / \mathrm{ml})$, and CD29 (MEM-101A, $0.3 \mu \mathrm{g} / \mathrm{ml})$. The inhibitors colchicine (CO) $(10 \mu \mathrm{M})$, cycloheximide $(\mathrm{CH})(10 \mu \mathrm{g} / \mathrm{ml})$, cytochalasin B (CT) $(1 \mu \mathrm{M})$, deoxyglucose (DG) $(10 \mathrm{mM})$, and ethylenediaminetetraacetic acid (ED) $(2 \mathrm{mM})$ were added to the cultures. Results are expressed as aggregation relative to control cultures in the presence of each aggregating antibody, but in the absence of inhibitor, and are the mean \pm SEM of triplicate cultures from a representative experiment. All values that differ significantly from controls $(P<0.01)$ are indicated by two asterisks. (B) U937 cell homotypic aggregation was measured under standard conditions as described under Materials and methods, in the presence of CD43 (161-46 and HI161, 1.0 $\mu \mathrm{g} / \mathrm{ml})$. Cytochalasin $\mathrm{B}$ and deoxyglucose were added at different concentrations $1 \mathrm{~h}$ prior to the mAb. Results are expressed as aggregation relative to control cultures in the presence of each aggregating antibody, but in the absence of the modulating agent, and are the mean \pm SEM of triplicate cultures. All values which differ significantly from controls $(P<0.01)$ are indicated by two asterisks or by one asterisk $(P<0.05)$. (C) U937 cell homotypic aggregation was measured under standard conditions as described under Materials and methods, in the presence of CD43 (161-46, $1.0 \mu \mathrm{g} / \mathrm{ml})$. Calmodulin inhibitors W-7 and chlorpromazine were added at different concentrations $1 \mathrm{~h}$ prior to the $\mathrm{mAb}$. Results are expressed as aggregation relative to control cultures in the presence of each aggregating $\mathrm{mAb}$, but in the absence of the modulating agent, and are the mean \pm SEM of triplicate cultures. All values which differ significantly from controls $(P<0.01)$ are indicated by two asterisks or by one asterisk $(P<0.05)$.

Neither compound inhibited the aggregation; in fact, both enhanced CD43-induced aggregation significantly (Fig. $5 \mathrm{~A})$, thus suggesting that serine/threonine phosphorylation may indeed participate in CD43-induced aggregation but as a negative rather than promoting signal.

Both H-7 and H-89 are serine/threonine kinase inhibitors with relatively broad specificity, and the effects are in the $25 \%-50 \%$ range, albeit statistically significant. Therefore, in further experiments the role of protein kinase A (PKA) was also explored, using some better-characterized inhibitors. Three compounds were used for this purpose. These were the most specific PKA inhibitor, KT5720, and two PKA activators, $\mathrm{PGE}_{2}$ and forskolin. None of these reagents affected the CD43-induced homotypic U937 aggregation (Fig. 5B), suggesting that PKA is not involved in this signaling pathway.

To dissect the PKC role further, a panel, which included both broad-spectrum and isozyme-specific PKC inhibitors, was used. Fig. 5C shows that none of these PKC inhibitors decrease cluster formation. Rather, these inhibitors potentiated CD43-induced aggregation strongly. In particular, the broad specificity PKC inhibitor staurosporin increased homotypic U937 aggregation massively. Both isozyme-specific PKC inhibitors (rottlerin, a PKC $\delta$ inhibitor, and myristoylated PKC peptide inhibitor 19-27, an inhibitor of PKC $\alpha / \beta)$ enhanced the aggregation. Furthermore, the diacylglycerol-specific inhibitor calphostin $\mathrm{C}$ had the same effect, as did the $\mathrm{Ca}^{2+}$ inhibitor Go6876. Thus, several PKC isoforms $(\alpha, \beta$, and $\delta)$ appear to be involved in negative regulation of CD43-induced signaling.

To confirm further that PKC is not involved as positive regulator, the translocation of several PKC isoforms $(\alpha, \beta$, $\delta$, and $\zeta$ ), which have been reported to participate in homotypic cell clustering formation and/or cell adhesion [42,43], was also examined. There was no difference between normal and CD43 treatment groups, under conditions where control PMA treatment induced the translocation of these PKC isoforms (data not shown). Thus, unlike other forms of homotypic U937 aggregation mediated by CD29 or CD98 [31], CD43-induced aggregation is not mediated by activated PKC.

The possible relationship between PKC activity and protein tyrosine phosphatase activity was also examined in the same assays. Fig. 5D shows that rottlerin cotreatment did not affect the inhibitory effect of dephostatin, thus indicating that the protein tyrosine phosphatase activation is itself PKC-independent.

CD43 ligation activates MAPK, but this is not linked to induction of homotypic aggregation

CD43 ligation is also known to induce MAPK/ERK and/or MAPK/p38 activation [44], with resultant regulation of actin polymerization. Therefore, involvement of these 
(A)

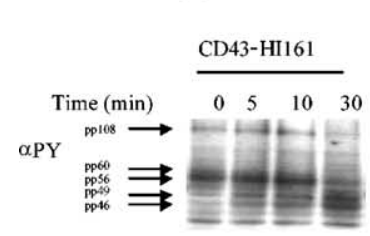

(B)

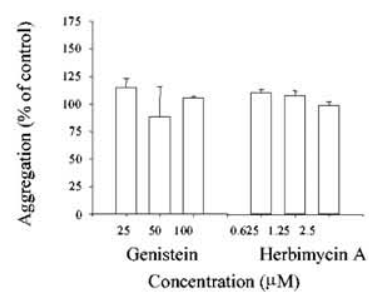

(C)

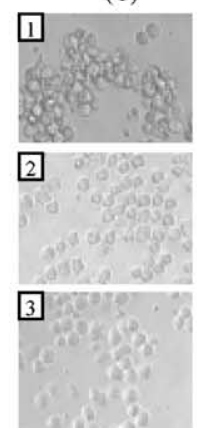

(D)

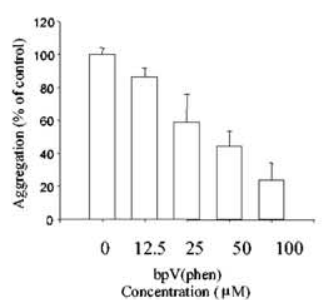

(E)

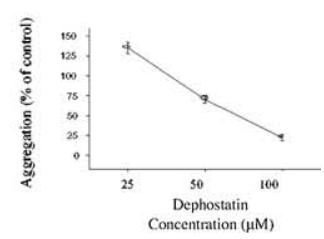

Fig. 4. CD43 elicits rapid tyrosine phosphorylation and dephosphorylation, but only dephosphorylation is pharmacologically linked to induction of homotypic aggregation. (A) U937 cells $\left(5 \times 10^{6}\right)$ were incubated in the presence of CD43 mAb (HI161, $\left.2.5 \mu \mathrm{g} / \mathrm{ml}\right)$ for various time periods indicated. Cells were lysed and analyzed for phosphotyrosine proteins as described under Materials and methods. Molecular weights of the major phosphorylated species are shown on the left and were calculated by image analysis of the Western blot, using molecular weight standards (not shown) to calibrate the software. (B) U937 cells were incubated with genistein or herbimycin A at a range of different concentrations in the presence or absence of CD43 mAb (HI161, $0.5 \mu \mathrm{g} / \mathrm{ml})$ for $3 \mathrm{hours}$ and aggregation was measured under standard conditions as described under Materials and methods. The results show means \pm SEM for triplicate cultures. (C) U937 cells were incubated with phosphatase inhibitors dephostatin $(100 \mu \mathrm{M})$ or potassium bisperoxo-(1,10-phenanthroline)-oxovanadate [bpV(phen)] $(100 \mu \mathrm{M})$ in the presence or absence of CD43 mAb (HI161, $0.5 \mu \mathrm{g} / \mathrm{ml})$ for $3 \mathrm{~h}$, as described under Materials and methods. Images of cells in culture at this time point were obtained using an inverted phase contrast microscope, attached to a video camera, and captured using NIH Image software. (D) U937 cells were incubated with tyrosine phosphatase inhibitor $\mathrm{bpV}($ phen) at a range of different concentrations in the presence or absence of CD43 mAb (HI161, 0.5 $\mu \mathrm{g} / \mathrm{ml}$ ) for $3 \mathrm{~h}$, and aggregation was measured under standard conditions as described under Materials and methods. The results show means \pm SEM for triplicate cultures. (E) U937 cells were incubated with the phosphatase inhibitor dephostatin at a range of different concentrations in the presence of CD43 (HI161, $0.5 \mu \mathrm{g} / \mathrm{ml}$ ), and aggregation was measured under standard conditions as described under Materials and methods. Results are expressed as aggregation relative to control cultures in the presence of each aggregating $\mathrm{mAb}$, but in the absence of the modulating agents, and are the mean \pm SEM of triplicate cultures.

MAPK pathways in CD43-induced homotypic U937 aggregation was examined. CD43 (HI161) treatment induced ERK activation as judged by increased phospho-ERK1/2 levels at $5 \mathrm{~min}$ and decreased by $30 \mathrm{~min}$ to less than normal, suggesting that protein tyrosine phosphatase activity is involved (data not shown). A similar pattern was also shown in the immunoblot with anti-phospho-p38 mAb. However, Fig. 6 shows that pharmacological testing with the inhibitors PD98059 (which acts via MEK1/2) and SB203589 (which acts via p38 MAPKs) did not affect CD43-induced homotypic U937 aggregation, irrespective of which antibody was used and whether the inhibitors were tested in FCS-free or $10 \%$ FCS-supplemented conditions.

\section{CD43 ligation increases surface levels of adhesion molecules}

One mechanism that might lead to an increase in homotypic U937 aggregation is via an increase in expression of other adhesion moieties on the cell surface. Therefore, the consequences of CD43 ligation were examined with respect to expression of CD18, CD29, CD98, and CD147. Table 1 shows that there was an increase in expression of all these molecules as evidenced by MFI levels. This increase was still present at $24 \mathrm{~h}$ after CD43 ligation (data not shown). In contrast, the cell surface level of CD45 was not affected, confirming that the CD43-mediated up-regulation was selective. Furthermore, control experiments ligating the other adhesion molecules did not lead to similar significant alteration in the levels of either the adhesion moieties themselves or of CD45 (data not shown).

\section{CD43 ligation increases CD29- and CD98-induced homotypic aggregation in an additive fashion}

To clarify the functional relationship between CD43 and the other adhesion moieties further, CD43 ligation was performed in the presence of aggregating and of blocking mAbs to CD18, CD29, CD43, CD98, and CD147 and in the presence of mAbs that did not affect aggregation. The results with CD18 mAbs showed 30\%-40\% inhibition, consistent with previous reports that CD43-induced aggregation was partially CD18-dependent $[44,45]$. However, none of the mAbs that had previously been shown to block homotypic U937 aggregation [31] had an inhibitory effect on CD43-induced aggregation at the same concentrations they did block CD29- and CD98-induced aggregation (data not shown). Furthermore, CD43- (161-46 or HI161) induced homotypic U937 aggregation was not affected by three CD43 mAbs (148-1B6, 148-1C3, 148-3D4) that are not able to trigger homotypic aggregation.

Another aspect of the combined antibody studies is illustrated in Fig. 7, where there was concomitant treatment of U937 cells with the CD43 mAb (146-16) and the mAbs specific for either CD29 (MEM-101A) or CD98 (AHN-18) that are known to induce homotypic aggregation. In these experiments the concentration of "primary" aggregating antibody was $50 \%$ of the optimum concentration used [31], and the results are expressed as a percentage of cells in aggregates. In the presence of CD43 the degree of aggregation was increased significantly. Thus the increased surface levels noted above (Table 1) may contribute in an additive fashion to the $\mathrm{CD} 43$-induced response. 
A

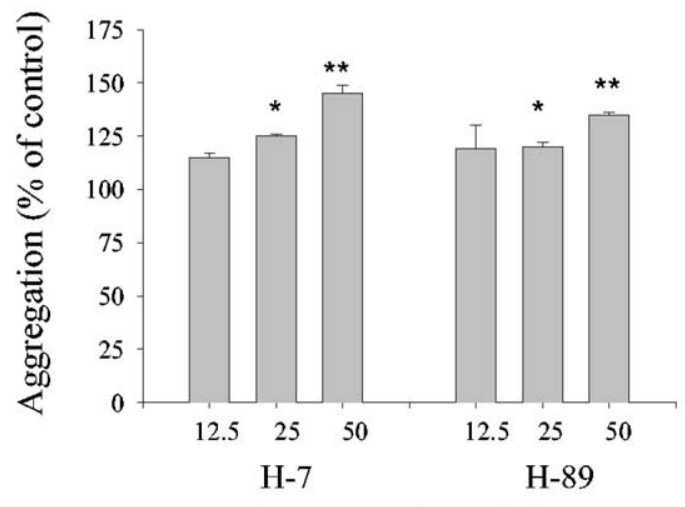

Concentration $(\mu \mathrm{M})$

B

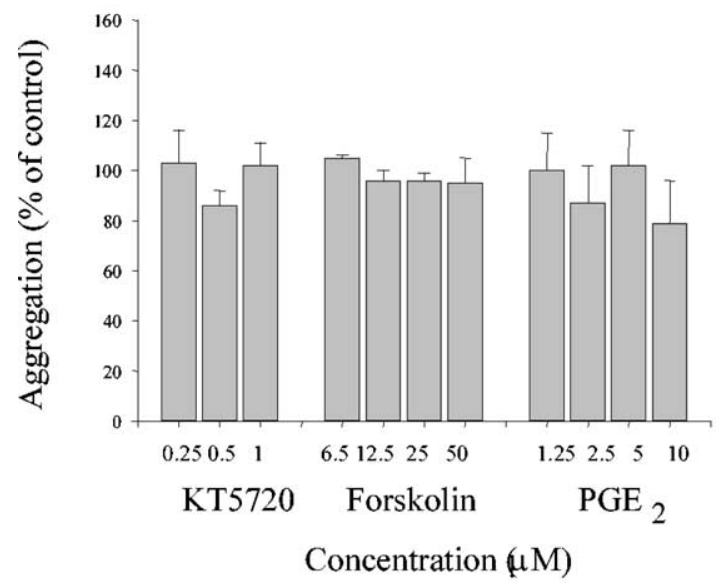

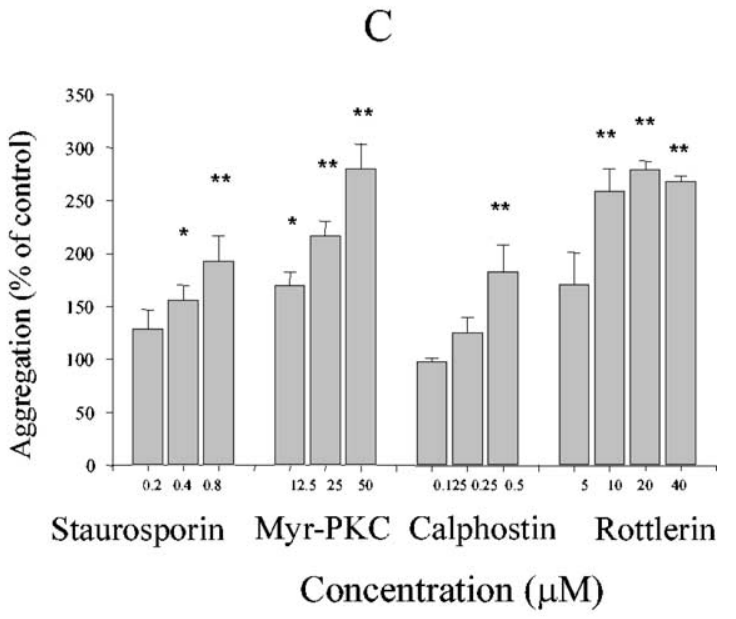

D

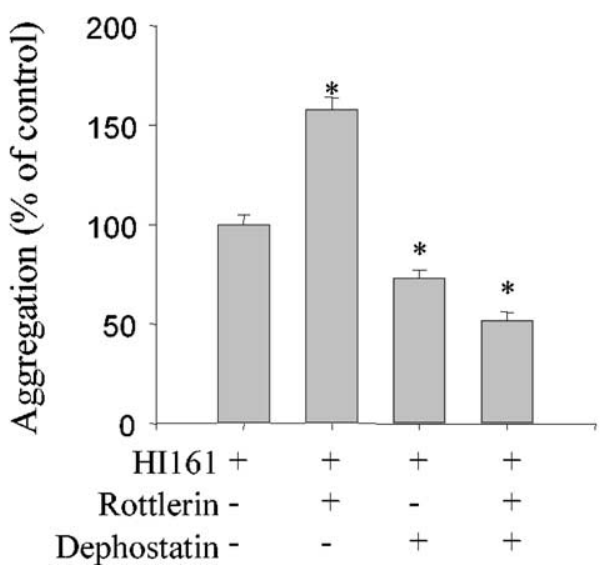

Fig. 5. Protein kinase C negatively regulates CD43-induced aggregation. (A) U937 cells were incubated with the serine/threonine kinase inhibitors H-7 and $\mathrm{H}-89$ at a range of different concentrations in the presence or absence of CD43 mAb (161-46, $0.5 \mu \mathrm{g} / \mathrm{ml})$, and aggregation was measured under standard conditions as described under Materials and methods. Results are expressed as aggregation relative to control cultures in the presence of each aggregating antibody, but in the absence of the modulating agent, and are the mean \pm SEM of triplicate cultures. All values that differ significantly from controls $(P<$ $0.01)$ are indicated by two asterisks or by one asterisk $(P<0.05)$. (B) U937 cells were incubated with the protein kinase A inhibitor KT5720 and with the protein kinase A activators forskolin and $\mathrm{PGE}_{2}$ at a range of different concentrations, in the presence or absence of CD43 mAb (161-46, 0.5 $\left.\mu \mathrm{g} / \mathrm{ml}\right)$ and aggregation was measured under standard conditions as described under Materials and methods. Results are expressed as aggregation relative to control cultures in the presence of each aggregating antibody, but in the absence of the modulating agent, and are the mean \pm SEM of triplicate cultures. (C) U937 cells were incubated with the protein kinase C isozyme inhibitors staurosporin, myristoylated protein kinase C inhibitor 19-27, calphostin C, and rottlerin, at a range of concentrations, in the presence or absence of CD43 mAb $(161-46,0.5 \mu \mathrm{g} / \mathrm{ml})$ and aggregation was measured under standard conditions as described under Materials and methods. Results are expressed as aggregation relative to control cultures in the presence of each aggregating antibody, but in the absence of the modulating agent, and are the mean \pm SEM of triplicate cultures. All values that differ significantly from controls $(P<0.01)$ are indicated by two asterisks or by one asterisk $(P<0.05)$. (D) U937 cells were incubated with CD43 mAb $(\mathrm{HI} 161,0.5 \mu \mathrm{g} / \mathrm{ml})$ in the presence or absence of the phosphatase inhibitor dephostatin $(100 \mu \mathrm{M})$ and of rottlerin $(10 \mu \mathrm{M})$, and aggregation was measured under standard conditions as described under Materials and methods. Results are expressed as aggregation relative to control cultures in the presence of the aggregating mAb, but in the absence of the modulating agents, and are the mean \pm SEM of triplicate cultures.

\section{Discussion}

In this study we have investigated the molecular mechanisms that regulate the well-established role of the major transmembrane sialoglycoprotein CD43 in cell-cell interaction. For this purpose we used the model system where we induced homotypic aggregation of the U937 monoblastoid cell that we have explored recently in relationship to CD98 [31].

There were several important features of the CD43induced homotypic U937 aggregation that distinguish it from that seen with either CD29 or CD98 in the same assay. First, with respect to metabolic processes, the CD43 model is less sensitive to energy depletion. Second, it is not sen- 

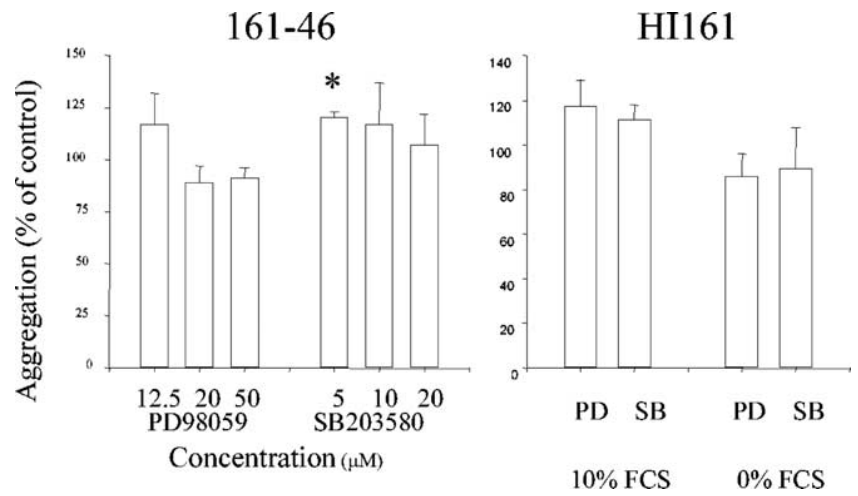

Fig. 6. The activation of MAPK by CD43 ligation is not required for CD43-induced homotypic aggregation. U937 cells were treated with a range of concentrations of the MAPK inhibitors PD98059 (PD) and SB203580 (SB) for $30 \mathrm{~min}$ before the addition of CD43 mAb (161-46, 0.5 $\mu \mathrm{g} / \mathrm{ml})$. In some experiments the U937 cells were cultured in serum-free medium for $4 \mathrm{~h}$ prior to the addition of the inhibitors $\mathrm{PD}(50 \mu \mathrm{M})$ and $\mathrm{SB}$ $(20 \mu \mathrm{M})$. Aggregation was measured under standard conditions as described under Materials and methods. Results are expressed as aggregation relative to control cultures in the presence of each aggregating antibody, but in the absence of the modulating agent, and are the mean \pm SEM of triplicate cultures.

sitive to the same forms of cytoskeletal injury. In fact, high concentrations of cytochalasin B strongly augmented CD43-induced cell aggregation, whereas CD29- and CD98induced aggregation were strongly inhibited. Third, although several intracellular signaling pathways were triggered by CD43 ligation, only tyrosine dephosphorylation was linked to induction of homotypic aggregation. In addition, the serine/threonine phosphorylation pathway and activation of protein kinase $\mathrm{C}$ acted as a negative regulatory mechanism of CD43-induced aggregation, since inhibitors of this pathway had an amplifying effect. Fourth, the adhesive interaction, which is known to be partially $\beta_{2}$-integrindependent $[44,45]$, does not appear to be mediated by $\beta_{1}$ or by other adhesion moieties such as CD44, CD98, and $\mathrm{CD} 147$, which are among the predominant molecules involved in adhesion and expressed on U937 cells [31]. Blocking antibodies against these molecules had no effect on the CD43-induced response. However, the engagement of CD43 (but not CD29, CD98, and CD147) did up-regulate surface levels of adhesion molecule expression, and this may account for the synergistic increase in U937 homotypic aggregation induced by combinations of CD43 with either CD29 or CD98.

Although CD43 was identified several years ago, and the features of the molecule have been characterized in detail (reviewed in Horejsi and Stockinger [32]) the question as to whether the molecule has a predominant proadhesive or antiadhesive effect-in either physiological or pathological circumstances-remains unresolved [34]. Even with respect to homotypic aggregation per se, the results are equivocal. CD43 mAbs are known to induce such aggregation of neutrophils and lymphocytes, and the effects were abrogated by $\mathrm{F}(\mathrm{ab})$ treatment, but maintained by $\mathrm{F}\left(\mathrm{ab}^{\prime}\right)_{2}$, suggesting a cross-linking event, rather than a direct physical effect of mAb binding to CD43 [44]; but even this effect has both CD18-dependent and CD18-independent (i.e., integrin-mediated adhesive) components. Bivalent CD43 mAb also induces homotypic aggregation of dendritic cells and dendritic cell maturation with enhancement of their T-cellactivating role in primary allogeneic and autologous responses, and in presentation of an HIV-1 peptide [46]. This study documented that the expression of several costimulatory molecules on dendritic cells was either induced or increased, and cytokine synthesis (including IL-10 as well as the conventional activating moieties) was increased, but changes in expression of integrin adhesion molecules were not described. The molecular mechanism of the CD43induced aggregation, including questions such as those about the relative balance between different signal transduction pathways, also remained very poorly understood. In T cells a clear association between CD43, protein tyrosine phosphorylation, downstream transcription factors, and activation has been documented, but this was not correlated with a morphological clustering event and addressed signaling molecules that are implicated particularly in $\mathrm{T}$ cell activation. In dendritic cells there is a rise in intracellular calcium, and protein tyrosine phosphorylation does occur, but protein tryrosine phosphatase activity and protein kinase $\mathrm{C}$ activity were not examined.

The possibility that CD43 is antiadhesive stems from the observation that it is heavily glycosylated. Hence, a high

Table 1

CD43 ligation increases surface levels of adhesion molecules

\begin{tabular}{|c|c|c|c|c|c|}
\hline Molecule & CD43 & CD29 & CD44 & CD98 & CD147 \\
\hline CD98 & $110.8 \pm 3.0^{* *}$ & $100.6 \pm 2.0$ & $97.3 \pm 1.8$ & NT & $94.7 \pm 1.8$ \\
\hline CD29 & $118.5 \pm 2.1^{* *}$ & NT & $98.5 \pm 0.6$ & $104.1 \pm 3.1$ & $95.6 \pm 0.7$ \\
\hline CD18 & $119.3 \pm 0.8^{* *}$ & $114.5 \pm 3.1^{* *}$ & $97.9 \pm 1.6$ & $101.4 \pm 1.4$ & $96.4 \pm 0.6$ \\
\hline CD45 & $102.7 \pm 4.1^{* *}$ & $104.2 \pm 2.1$ & $101.7 \pm 3.5$ & $102.1 \pm 2.7$ & $96.4 \pm 0.6$ \\
\hline
\end{tabular}

Note. U937 cells $\left(10^{6}\right)$ were incubated with an aggregating CD43 mAb (H161, $\left.0.5 \mu \mathrm{g} / \mathrm{ml}\right)$ for $3 \mathrm{~h}$, and cell surface molecule expression was measured using directly labeled mAbs under standard conditions as described in methods. In control experiments the U937 cells were treated with mAbs to CD29 (MEM-101A), CD44 (E1/6), CD98 (AHN-18), and CD147 (MEM-M6/1) (all at $0.5 \mu \mathrm{g} / \mathrm{ml}$ ) for $7 \mathrm{~h}$. MFI values were calculated using WIN-MDI software on a minimum of 7500 cells. The results are expressed as percentages of control MFI \pm SEM $(n=6)$. NT, not tested. $* * P<0.01$ 


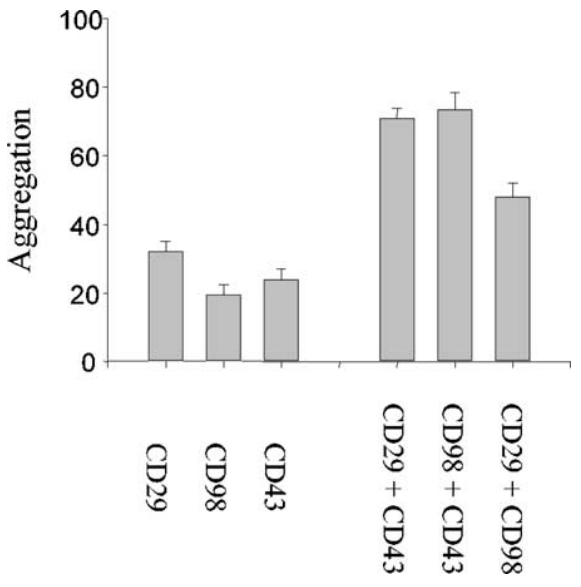

Fig. 7. Relationship between CD43 and other cell surface molecules. U937 cells were treated with CD29 (MEM-101A), CD98 (AHN-18), and CD43 (HI161) $\mathrm{mAb}$ (all at $0.25 \mu \mathrm{g} / \mathrm{ml}$ ) either alone or in combination, for $3 \mathrm{~h}$. Aggregation was measured under standard conditions as described under Materials and methods. Results are expressed as percentages of cells in aggregates in the presence of $\mathrm{mAb}$, either alone or in combination, and are the mean \pm SEM of triplicate cultures.

proportion of the negative cell surface charge on hematopoietic cells is attributed to CD43, and this would mitigate against cell-cell adhesion. The less heavily glycosylated 95- to $115-\mathrm{kDa} \mathrm{CD} 43$ isoform would have a proadhesive effect, in contrast with the antiadhesive role of the 130- to $140-\mathrm{kDa}$ isoform. Superficially our data would support this antiadhesive view, since CD43 ligation would mask some of this negative charge and hence facilitate cell-cell contact and adhesion via conventional pathways. However, when the data reported here are considered in more detail, this view does not seem to be correct. The CD43 mAbs, which do induce aggregation (161-46, HI161, MEM-59, and 84$3 \mathrm{C} 1$ ), all recognize the $110-\mathrm{kDa}$ isoform [30]. Some of the mAbs (e.g., 148-1C3 and RPD/AD9) that recognize neuraminidase-sensitive epitopes, the most negatively charge portions of CD43, did not induce homotypic clustering. This agrees with the report that both CD43 (161-46), which recognizes a sialic-acid-independent epitope, and CBF78, which binds to a neuraminidase-insensitive site, may have similar effects on adhesion [30].

Other possible mechanisms whereby CD43 ligation might abrogate an antiadhesion process could be to induce loss of surface CD43, either by proteolytic shedding [33,34] or by internalization. Correlation between the ability to induce homotypic aggregation and shedding of CD43 from the surface was not seen in this study. The combination of lack of correlation between quantitative expression and aggregation and the enhancing effect of cytochalasin B both argue against significant internalization. Hence, the CD43induced aggregation is not due to CD43 loss and resultant abolition of an antiadhesion process.

The alternative to the antiadhesive hypothesis is that CD43 ligation does induce intracellular signaling [47], which would promote either an adhesive process or a failure thereof depending on the nature of the signaling. Previous reports in other model systems $[22,29,46]$ have documented that calcium flux, PTK activity, and MAPK activity can occur in response to CD43 mAbs. In this study, although some of these previous observations were confirmed, unexpectedly there was a more direct correlation of homotypic aggregation with PTPase activation than with either of these kinases. This suggests that there is a special, different biochemical pathway for CD43-induced aggregation, unlike the integrin-mediated aggregation that requires the activation of MAPK (and PKC) [48,49]. The role of PTPase is supported both by the pharmacological data using the PTPase inhibitors bpV(phen) and dephostatin and by the biochemical evidence. It is noteworthy that ligation of CD45, which itself has intrinsic PTPase activity, has also been reported to have a proaggregatory effect [50-52].

Previous reports have suggested that activation of PKC by CD43 ligation may induce positive regulation of processes such as adhesion [53,54]. In contrast, in this study the nonselective PKC inhibitor staurosporin augmented CD43induced homotypic aggregation in a striking fashion. Although the mechanism of action of staurosporin was not investigated in detail in this study, the qualitatively identical data obtained when more specific PKC inhibitors were used support the hypothesis that staurosporin may be acting as an inhibitor of PKCs. Unfortunately staurosporin is known to have toxic effects at higher concentrations, which therefore determine the range that can be used in the assay-hence, it may have less effect than the specific inhibitors, which did not have the same toxicity problem. The combination of an inhibitory effect of rottlerin, which is a selective $\mathrm{PKC} \delta$ inhibitor [55,56], and of myristoylated peptides that are selective inhibitors of $\mathrm{PKC} \alpha / \beta$ [57] suggests that all three ( $\mathrm{PKC} \delta, \mathrm{PKC} \alpha$, and $\mathrm{PKC} \beta$ ) may be negatively involved, that is, as inhibitors of CD43-induced aggregation. This would imply that cell activation-as judged by enhanced PKC activity-would decrease the CD43-adhesive potential. Under normal conditions PMA-responsive PKC isoforms are known to be involved in hyperphosphorylation of the intracytoplasmic tail of CD43 [58,59]; it may be that to see any proadhesive effect, one needs to abrogate the PKCmediated negative regulation and thus induce a state of CD43 hypophosphorylation, and this could be achieved either by a direct (ligation) or indirect (blocking of PKC) route.

The exact molecular mechanism by which CD43 ligation mediates the increase of surface adhesion molecule expression remains to be elucidated. CD43-induced changes in these molecules do not appear to require new protein synthesis, as cycloheximide did not block aggregation. Furthermore, the change in phenotype did not affect CD43-induced homotypic aggregation directly, as only blocking antibodies to the $\beta 2$ integrin adhesion molecules diminished the CD43induced aggregation. It is possible that translocation of integrins trapped within the actin cytoskeleton on to the cell 


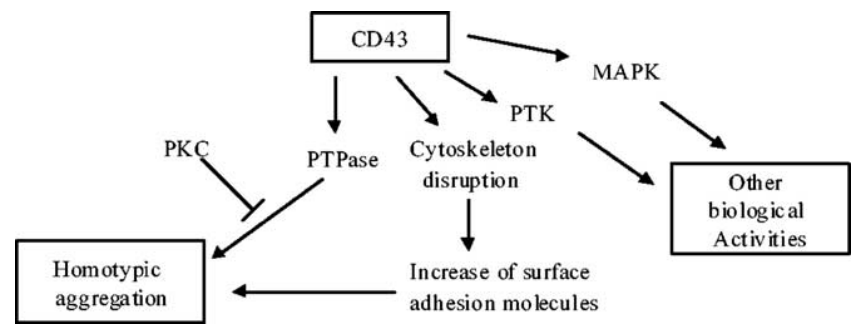

Fig. 8. Proposed model of signaling cascade in U937 cells during CD43 ligation. CD43 ligation promotes tyrosine phosphorylation, MAPK activation, and tyrosine dephosphorylation. These may all be involved in different CD43-induced biological activities. Tyrosine dephosphorylation appears to be linked to homotypic aggregation and this may in turn be connected to cytoskeletal disruption, which could lead to an increased surface expression of cell surface adhesion molecules. Further details are outlined in the text.

membrane may explain up-regulation of these molecules [60] and thus account for the present observations.

Thus, in summary, these data suggest CD43-induced model system of U937 homotypic aggregation, which would not only account for some of the conflicting previous studies, but also provide insight into an important component of the cell dynamics of the immune system. This is illustrated diagrammatically in Fig. 8. Our results support the view that the $110-\mathrm{kDa}$ form of CD43 promotes adhesion. CD43 ligation does lead to PTK activity, and MAPK activation, but the PTPase-dephosphorylating activity is what is required as a critical step in the initiation of cell-cell adhesion. This leads to CD43-mediated actin rearrangement, which may be involved in up-regulation of surface adhesion molecule levels. Both conventional and novel PKCs have a role as down-regulators of any CD43-ligationinduced events, and it may be that activation of these enzymes is what regulates CD43 signaling to a separate, parallel pathway, to induce cell migration or cell-matrix binding, rather than to the cell-cell interaction that has been documented here.

\section{References}

[1] J.A. Madri, D. Graesser, Cell migration in the immune system: the evolving inter-related roles of adhesion molecules and proteinases, Dev. Immunol. 7 (2000) 103-116.

[2] Z. Szekanecz, A.E. Koch, Cell-cell interactions in synovitis: endothelial cells and immune cell migration, Arthritis Res. 2 (2000) 368-373.

[3] P.D. King, D.R. Katz, Human tonsillar dendritic cell-induced T cell responses: analysis of molecular mechanisms using monoclonal antibodies, Eur. J. Immunol. 19 (1989) 581-587.

[4] A. Anichini, R. Mortarini, S. Alberti, A. Mantovani, G. Parmiani, T-cell-receptor engagement and tumor ICAM-1 up-regulation are required to by-pass low susceptibility of melanoma cells to autologous CTL-mediated lysis, Int. J. Cancer. 53 (1993) 994-1001.

[5] M. Sixt, B. Engelhardt, F. Pausch, R. Hallmann, O. Wendler, L.M. Sorokin, Endothelial cell laminin isoforms, laminins 8 and 10, play decisive roles in $\mathrm{T}$ cell recruitment across the blood-brain barrier in experimental autoimmune encephalomyelitis, J. Cell Biol. 153 (2001) 933-946.
[6] A. Hafezi-Moghadam, K.L. Thomas, A.J. Prorock, Y. Huo, K. Ley, L-selectin shedding regulates leukocyte recruitment, J. Exp. Med. 193 (2001) 863-872.

[7] K. Takenaka, M. Shibuya, Y. Takeda, S. Hibino, A. Gemma, Y. Ono, S. Kudoh, Altered expression and function of betal integrins in a highly metastatic human lung adenocarcinoma cell line, Int. J. Oncol. 17 (2000) 1187-1194.

[8] J.G. Cyster, D.M. Shotton, A.F. Williams, The dimensions of the T lymphocyte glycoprotein leukosialin and identification of linear protein epitopes that can be modified by glycosylation, EMBO J. 10 (1991) 893-890.

[9] D. Kenney, L. Cairns, E. Remold-O’Donnell, J. Peterson, F.S. Rosen, R. Parkman, Morphological abnormalities in the lymphocytes of patients with the Wiskott-Aldrich syndrome, Blood 68 (1986) 13291332.

[10] K.A. Siminovitch, W.L. Greer, B. Axelsson, L.A. Rubin, A. Novogrodsky, M. Peacocke, Selective impairment of CD43-mediated T cell activation in the Wiskott-Aldrich syndrome, Immunodeficiency 4 (1993) 99-108.

[11] S. Weber, B. Ruh, E. Dippel, B.M. Czarnetzki, Monoclonal antibodies to leucosialin (CD43) induce homotypic aggregation of the human mast cell line HMC-1: characterization of leucosialin on HMC-1 cells, Immunology 82 (1994) 638-644.

[12] E. Fanales-Belasio, G. Zambruno, A. Cavani, G. Girolomoni, Antibodies against sialophorin (CD43) enhance the capacity of dendritic cells to cluster and activate T lymphocytes, J. Immunol. 159 (1997) 2203-2211.

[13] T.K. van den Berg, D. Nath, H.J. Ziltener, D. Vestweber, M. Fukuda, I. van Die, P.R. Crocker, E. Fanales-Belasio, Cutting edge: CD43 functions as a $\mathrm{T}$ cell counterreceptor for the macrophage adhesion receptor sialoadhesin (Siglec-1), J. Immunol. 166 (2001) 3637-3640.

[14] B. Ardman, M.A. Sikorski, D.E. Staunton, CD43 interferes with T-lymphocyte adhesion, Proc. Natl. Acad. Sci. USA 89 (1992) 50015005.

[15] N. Manjunath, R.S. Johnson, D.E. Staunton, R. Pasqualini, B. Ardman, Targeted disruption of CD43 gene enhances T lymphocyte adhesion, J. Immunol. 151 (1993) 1528-1534.

[16] N. Manjunath, M. Correa, M. Ardman, B. Ardman, Negative regulation of T-cell adhesion and activation by CD43, Nature 377 (1995) 535-538.

[17] B. Axelsson, R. Youseffi-Etemad, S. Hammarstrom, P. Perlmann, Induction of aggregation and enhancement of proliferation and IL-2 secretion in human T cells bny antibodies to CD43, J. Immunol. 141 (1988) 2912-2917.

[18] Y.H. Nong, E. Remold-O’Donnell, T.W. LeBien, H.G. Remold, A monoclonal antibody to sialophorin (CD43) induces homotypic adhesion and activation of human monocytes, J. Exp. Med. 170 (1989) 259-267.

[19] J.K. Park, Y.J. Rosenstein, E. Remold-O’Donnell, B.E. Bierer, F.S. Rosen, S.J. Burakoff, Enhancement of T-cell activation by the CD43 molecule whose expression is defective in Wiskott-Aldrich syndrome, Nature 350 (1991) 706-709.

[20] A.I. Sperling, J.M. Green, R.L. Mosley, P.L. Smith, R.J. DiPaolo, J.R. Klein, J.A. Bluestone, C.B. Thompson, CD43 is a murine T cell costimulatory receptor that functions independently of CD28, J. Exp. Med. 182 (1995) 139-146.

[21] R. Youseffi-Etemad, B. Axelsson, Parallel pattern of expression of CD43 and of LFA-1 on the CD45RA+ (naïve) and CD45RO+ (memory) subsets of human CD4+ and CD8 + cells: correlation with the aggregative response of the cells to CD43 monoclonal antibodies, Immunology 87 (1996) 439-446.

[22] T.J. Brown, W.W. Shuford, W.C. Wang, S.G. Nadler, T.S. Bailey, H. Marquardt, R.S. Mittler, Characterization of a CD43/leukosialin-mediated pathway for inducing apoptosis in human T-lymphoblastoid cells, J. Biol. Chem. 271 (1996) 27686-27695. 
[23] E.C. Thurman, J. Walker, S. Jayaraman, N. Manjunath, B. Ardman, J.M. Green, Regulation of in vitro and in vivo $\mathrm{T}$ cell activation by CD43, Int. Immunol. 10 (1998) 691-701.

[24] Y.W. He, M.J. Bevan, High level expression of CD43 inhibits T cell receptor/CD3-mediated apoptosis, J. Exp. Med. 190 (1999) 19031908.

[25] J.M. Serrador, M. Nieto, J.L. Alonso-Lebrero, M.A. del Pozo, J. Calvo, H. Furthmayr, R. Schwartz-Albiez, F. Lozano, R. Gonzalez-Amaro, P. Sanchez-Mateos, F. Sanchez-Madrid, CD43 interacts with moesin and ezrin and regulates its redistribution to the uropods of $\mathrm{T}$ lymphocytes at the cell-cell contacts, Blood 91 (1998) 4632-4644.

[26] M.A. del Pozo, M. Vicente-Manzanares, R. Tejedor, J.M. Serrador, F. Sanchez-Madrid, Rho GTPases control migration and polarization of adhesion molecules and cytoskeletal ERM components in T lymphocytes, Eur. J. Immunol. 29 (1999) 3609-3620.

[27] S. Yonemura, S. Tsukita, S. Tsukita, Direct involvement of ezrin/ radixin/moesin (ERM)-binding membrane proteins in the organization of microvilli in collaboration with activated ERM proteins, J. Cell Biol. 145 (1999) 1497-1509.

[28] E.N. Guan, W.H. Burgess, S.L. Robinson, E.B. Goodman, K.J. McTigue, A.J. Tenner, Phagocytic cell molecules that bind the collagenlike region of C1q: involvement in the C1q-mediated enhancement of phagocytosis, J. Biol. Chem. 266 (1991) 20345-2055.

[29] J. Tada, M. Omine, T. Suda, N. Yamaguchi, A common signaling pathway via Syk and Lyn tyrosine kinases generated from capping of the sialomucins CD34 and CD43 in immature hematopoietic cells, Blood 93 (1999) 3723-3735.

[30] J. Tkaczuk, Saati T. Al, I. Escargueil-Blanc, A. Salvayre, V. Horejsi, M. Durand, C. de Preval, E. Ohayon, G. Delsol, M. Abbal, The CBF.78 monoclonal antibody to human sialophorin has distinct properties giving new insights into the CD43 marker and its activation pathway, Tissue Antigens 54 (1999) 1-15.

[31] J.Y. Cho, D.A. Fox, V. Horejsi, K. Sagawa, K.M. Skubitz, D.R. Katz, B.M. Chain, The functional interactions between CD98, beta1-integrins, and CD147 in the induction of U937 homotypic aggregation, Blood 98 (2001) 374-382.

[32] V. Horejsi, H. Stockinger, CD43 workshop panel report, in: T. Kishimoto, et al. (Eds.), Leukocyte Typing VI: White Cell Differentiation Antigens: proceedings of the sixth international workshop and conference held in Kobe, Japan, 10-14 November 1996, Garland Publishing, New York, 1998, pp. 494-497.

[33] P. Rieu, F. Porteu, G. Bessou, P. Lesavre, L. Halbwachs-Mecarelli, Human neutrophils release their major membrane sialoprotein, leukosialin (CD43), during cell activation, Eur. J. Immunol. 22 (1992) 3021-3026.

[34] S. Lopez, S. Seveau, P. Lesavre, M.K. Robinson, L. HalbwachsMecarelli, CD43 (sialophorin, leukosialin) shedding is an initial event during neutrophil migration, which could be closely related to the spreading of adherent cells, Cell. Adhes. Commun. 5 (1998) $151-160$.

[35] S.C. Fagerholm, A. Prescott, P. Cohen, C.G. Gahmberg, An essential role for calmodulin in regulating human $\mathrm{T}$ cell aggregation, FEBS Lett. 491 (2001) 131-136.

[36] G. Pedraza-Alva, S. Sawasdikosol, Y.C. Liu, L.B. Merida, M.E. Cruz-Munoz, F. Oceguera-Yanez, S.J. Burakoff, Y. Rosenstein, Regulation of $\mathrm{Cbl}$ molecular interactions by the co-receptor molecule CD43 in human T cells, J. Biol. Chem. 276 (2001) 729-737.

[37] D.H. Yu, C.K. Qu, O. Henegariu, X. Lu, G.S. Feng, Protein-tyrosine phosphatase Shp-2 regulates cell spreading, migration, and focal adhesion, J. Biol. Chem. 273 (1998) 21125-21131.

[38] D.E. Jackson, C.M. Ward, R. Wang, P.J. Newman, T.D. Garver, The protein-tyrosine phosphatase SHP-2 binds platelet/endothelial cell adhesion molecule-1 (PECAM-1) and forms a distinct signaling com- plex during platelet aggregation: evidence for a mechanistic link between PECAM-1- and integrin-mediated cellular signaling, J. Biol. Chem. 272 (1997) 6986-6993.

[39] S. Osdoit, J.P. Rosa, Fibrin clot retraction by human platelets correlates with alpha(IIb)beta(3) integrin-dependent protein tyrosine dephosphorylation, J. Biol. Chem. 276 (2001) 6703-6710.

[40] M. Imoto, H. Kakeya, T. Sawa, C. Hayashi, M. Hamada, T. Takeuchi, K. Umezawa, Dephostatin, a novel protein tyrosine phosphatase inhibitor produced by Streptomyces. I. Taxonomy, isolation, and characterization, J. Antibiot. (Tokyo) 46 (1993) 1342-1346.

[41] T.D. Garver, Q. Ren, S. Tuvia, V. Bennett, Tyrosine phosphorylation at a site highly conserved in the L1 family of cell adhesion molecules abolishes ankyrin binding and increases lateral mobility of neurofascin, J. Cell Biol. 137 (1997) 703-714.

[42] C. Laudanna, D. Mochly-Rosen, T. Liron, G. Constantin, E.C. Butcher, Evidence of zeta protein kinase $\mathrm{C}$ involvement in polymorphonuclear neutrophil integrin-dependent adhesion and chemotaxis, J. Biol. Chem. 273 (1998) 30306-30315.

[43] M.L. Day, X. Zhao, C.J. Vallorosi, M. Putzi, C.T. Powell, C. Lin, K.C. Day, E-cadherin mediates aggregation-dependent survival of prostate and mammary epithelial cells through the retinoblastoma cell cycle control pathway, J. Biol. Chem. 274 (1999) 96569664.

[44] T.W. Kuijpers, M. Hoogerwerf, K.C. Kuijpers, B.R. Schwartz, J.M. Harlan, Cross-linking of sialophorin (CD43) induces neutrophil aggregation in a CD18-dependent and a CD18-independent way, J. Immunol. 149 (1992) 998-1003.

[45] W. De Smet, H. Walter, L. van Hove, A new CD43 monoclonal antibody induces homotypic aggregation of human leucocytes through a CD11a/CD18-dependent and independent mechanism, Immunology 79 (1993) 46-54.

[46] S. Corinti, E. Fanales-Belasio, C. Albanesi, A. Cavani, P. Angelisova, G. Girolomoni, Cross-linking of membrane CD43 mediates dendritic cell maturation, J. Immunol. 162 (1999) 6331-6336.

[47] J. Walker, J.M. Green, Structural requirements for CD43 function, J. Immunol. 162 (1999) 4109-4114.

[48] S. Miyamoto, H. Teramoto, J.S. Gutkind, K.M. Yamada, Integrins can collaborate with growth factors for phosphorylation of receptor tyrosine kinases and MAP kinase activation: roles of integrin aggregation and occupancy of receptors, J. Cell Biol. 135 (1996) 1633 1642.

[49] M.H. Pillinger, C. Capodici, P. Rosenthal, N. Kheterpal, S. Hanft, M.R. Philips, G. Weissmann, Modes of action of aspirin-like drugs: salicylates inhibit erk activation and integrin-dependent neutrophil adhesion, Proc. Natl. Acad. Sci. USA 95 (1998) 1454014545.

[50] P.D. King, A.H. Batchelor, P. Lawlor, D.R. Katz, The role of CD44, CD45, CD45RO, CD46 and CD55 as potential anti-adhesion molecules involved in the binding of human tonsillar T cells to phorbol 12-myristate 13-acetate-differentiated U937 cells, Eur. J. Immunol. 20 (1990) 363-368.

[51] J.M. Zapata, M.R. Campanero, M. Marazuela, F. Sanchez-Madrid, M.O. de Landazuri, B-cell homotypic adhesion through exon-A restricted epitopes of CD45 involves LFA-1/ICAM-1, ICAM-3 interactions, and induces coclustering of CD45 and LFA-1, Blood 86 (1995) 1861-1872.

[52] C. Herold, A. Elhabazi, G. Bismuth, A. Bensussan, L. Boumsell, CD100 is associated with CD45 at the surface of human T lymphocytes: role in T cell homotypic adhesion, J. Immunol. 157 (1996) 5262-5268.

[53] M. Babina, S. Weber, K. Mammeri, B.M. Henz, Signal transduction via CD43 (leukosialin, sialophorin) and associated biological effects in human mast cell line (HMC-1), Biochem. Biophys. Res. Commun. 243 (1998) 163-169. 
[54] M.A. Santana, G. Pedraza-Alva, N. Olivares-Zavaleta, V. MadridMarina, V. Horejsi, S.J. Burakoff, Y. Rosenstein, CD43-mediated signals induce DNA binding activity of AP-1, NF-AT, and NFkappa B transcription factors in human T lymphocytes, J. Biol. Chem. 275 (2000) 31460-31468.

[55] M.E. Reyland, S.M. Anderson, A.A. Matassa, K.A. Barzen, D.O. Quissell, Protein kinase C delta is essential for etoposide-induced apoptosis in salivary gland acinar cells, J. Biol. Chem. 274 (1999) 19115-19123.

[56] E. Kontny, M. Kurowska, K. Szczepanska, W. Maslinski, Rottlerin, a PKC isozyme-selective inhibitor, affects signaling events and cytokine production in human monocytes, J. Leukocyte Biol. 67 (2000) 249-258.
[57] N.E. Ward, C.A. O'Brian, Inhibition of protein kinase C by Nmyristoylated peptide substrate analogs, Biochemistry 32 (1993) 11903-11909.

[58] T.A. Chatila, R.S. Geha, Phosphorylation of T cell membrane proteins by activators of protein kinase C, J. Immunol. 140 (1988) $4308-4314$.

[59] B. Axelsson, P. Perlmann, Persistent superphosphorylation of leukosialin (CD43) in activated T cells and in tumour cell lines, Scand. J. Immunol. 30 (1989) 539-547.

[60] T. Ng, D. Shima, A. Squire, P.I. Bastiaens, S. Gschmeissner, M.J. Humphries, P.J. Parker, PKCalpha regulates beta1 integrin-dependent cell motility through association and control of integrin traffic, EMBO J. 18 (1999) 3909-3923. 